\title{
Colorectal cancer in Porto Alegre and Fortaleza, Brazil: incidence trends and distribution pattern from 1990 to 1999
}

\author{
Câncer de cólon e reto em Porto Alegre e \\ Fortaleza, Brasil: tendência das taxas de \\ incidência e padrão de distribuição \\ no período 1990-1999
}

\footnotetext{
1 Coordenação de Prevenção e Vigilância, Instituto Nacional de Câncer, Rio de Janeiro, Brasil.

2 Instituto de Estudos em Saúde Coletiva, Universidade Federal do Rio de Janeiro, Rio de Janeiro, Brasil.

Correspondence K. V. Bloch

Instituto de Estudos em Saúde Coletiva, Universidade Federal do Rio de Janeiro. Rua Eurico Cruz 47, apto. 501, Rio de Janeiro, $R J$

22461-200, Brasil.

kbloch@globo.com
}

\section{Abstract}

The aim of this study was to describe the incidence distribution of colorectal cancer in Fortaleza, Ceará State, and Porto Alegre, Rio Grande do Sul State, Brazil, and the time trend in the disease from 1990 to 1999. Mean annual ageadjusted incidence rates and estimated annual percent change were calculated by gender, using population-based cancer registries. EAPC showed an increase in the rates in Porto Alegre and Fortaleza for men, $+4.2 \%(p=0.14)$ and $+9.3 \%(p \leq$ $0.001)$, and women, $+4.6 \%(p=0.11)$ and $+5.3 \%$ $(p=0.15)$, respectively. The mean adjusted incidence rates were three times higher in Porto Alegre than in Fortaleza both for men (25.1 vs. 8.6/100 thousand) and women (19.9 vs. 7.1/100 thousand). This rise in incidence rates may be due to early cancer detection strategies, lifestyle changes, and alterations in the population age structure. A population profile similar to that of developed countries may explain the higher incidence rates in Porto Alegre. However, Fortaleza showed the largest increases during the period studied.

Colorectal Neoplasms; Diseases Registries; Incidence
Rejane de Souza Reis 1

Marceli de Oliveira Santos 1

Katia Vergetti Bloch 2

\section{Introduction}

Colorectal cancer is the third most common form of cancer in the world in both men and women and the second most common in developed countries. The geographic distribution patterns for men and women are similar 1. In Brazil, for 2006, approximately 11 thousand new cases of colorectal cancer were estimated in male and 14 thousand in females 2 .

Population-Based Cancer Registries (PBCR) are systematized centers for the collection, storage, and analysis of occurrence and characteristics of new cancer cases in a population, whose objective is to estimate the total number of cases, as well as distributions and time trends in the populations belonging to their geographic coverage areas 3 .

This study selected the cities of Fortaleza, Ceará State, and Porto Alegre, Rio Grande do Sul State, Brazil, since they both have long experience with cancer registries. Both PBCRs have data available for the same period (1990 to 1999) and use the SisBasepop data collection and analysis application (National Cancer Institute, Rio de Janeiro, Brazil; http://www.inca.gov.br/cgi/sis basepop.asp), thus allowing standardization and comparison. Meanwhile, the two cities have distinct socioeconomic, demographic, and dietary and nutritional profiles 4 .

The incorporation of new technologies and changes in colorectal cancer trends (both for in- 
cidence and mortality) justify the need to expand the knowledge on this type of cancer. In addition, the literature shows few studies on colorectal cancer incidence in the regions and State capitals of Brazil. Therefore, the aim of this study was to describe the distribution of colorectal cancer incidence in the cities of Fortaleza and Porto Alegre and evaluate the time trend in the disease from 1990 to 1999.

\section{Methods}

Data on colorectal cancer incidence were obtained from the PBCRs in Fortaleza and Porto Alegre. Data quality was assessed using the criteria of the International Agency for Research on Cancer (IARC) 5 .

The target variables were collected by the PBCRs using a standardized data collection form, and included gender, age, and primary tumor site. The PBCRs code the incident cases based on the International Classification of Diseases for Oncology (ICD-O). For 1990-1995, the ICD-O 1st Edition was used (ICD-O1), and for 1996-1999, the ICD-O 2nd Edition (ICD-O2). After this coding, the SisBasepop application automatically converts the incident cases to the International Classification of Diseases, 10th Revision (ICD-10), according to international conversion standards 6 .

Incident cases of colorectal cancer were defined according to the following code intervals from ICD-10: C18-C20 (C18 - malignant neoplasm of the colon, C19 - malignant neoplasm of the rectosigmoid junction, and C20 - malignant neoplasm of the rectum), recorded with a diagnosis of primary malignant tumor from 1990 to 1999 in the cities of Fortaleza and Porto Alegre. The sample excluded cases of in situ tumors, since they present different characteristics and prognoses.

Specific mean incidence rates were calculated according to ten-year age group and also in two distinct age groups (59 years or younger and 60 years and older), both disaggregated by gender and city.

Disaggregated analysis by age group, gender, and city was used to verify the time trend over the period. This trend is summarized using the estimated annual percent change (EAPC) method, calculated by linear regression of the log rates with the least squares method.

Calculation of the mean incidence rates used the population data from the 1991 National Census, the 1996 population count, and the intercensus estimates provided by the Brazilian Institute of Geography and Statistics, or National Census Bureau (IBGE; http://www.ibge.gov.br).
The rates were adjusted using the world standard population, as proposed by Segi 7 and modified by Doll et al. ${ }^{8}$. Age adjustment used the direct method. The $95 \%$ confidence intervals $(95 \% \mathrm{CI})$ were calculated for the mean age-adjusted incidence rate (AIR). The standard error (SE) used here was based on an approximation of the Poisson distribution 9. Calculation of the $95 \% \mathrm{CI}$ can be expressed as: AIR $\pm Z_{\alpha / 2}$ [SE (AIR)]; and the rate's $\mathrm{SE}$ is expressed as:

$\sqrt{\frac{\left.\sum \text { [age-specific rate } \times \text { (age group standard pop. }\right)^{2} \times(100,000-\text { age-specific rate)/local pop., period, age group] }}{\left(\sum \text { standard pop. }\right)^{2}}}$

where: age-specific rate $=$ specific rate per age group; age group standard pop. = standard population per age group; local pop., period, age group = local population in the age group in the study period; standard pop. $=$ standard population .

The EAPC was calculated for the entire period (1990-1999) and broken down by gender. This index is calculated by adjustment of the linear regression to the natural log of the rates $(r)$, using the calendar year as the regressor variable; that is, $y=m x+b$ where: $y=\operatorname{Ln} r, x=$ calendar year, $m=$ angular coefficient, and $b=$ intercept. This calculation assumed that the rate increases or decreases in linear fashion from year to year, throughout the time interval under study ${ }^{10}$. Statistical analysis used S-Plus version 6.0 (Mathsoft Inc., Seattle, USA).

The trend in the historical series for each PBCR, disaggregated by gender, was constructed from the log of the adjusted rates. The log function was used intentionally to smooth the rates, since they fluctuate randomly, especially in the initial years.

\section{Results}

Table 1 shows the quality index results for PBCR quality.

Table 2 provides the descriptive characteristics of colorectal cancer incidence in Fortaleza and Porto Alegre from 1990 to 1999.

The mean age-specific colorectal cancer incidence rates for 1990 to 1999 show that the disease incidence begins to appear in the 50-59year age group in both genders in Fortaleza and Porto Alegre, and increases with age, reaching higher levels in men and women in Porto Alegre (Figure 1).

Analysis of colorectal cancer incidence showed an upward trend. Both Fortaleza and Porto Alegre showed an upward trend in both genders (Figure 1).

Porto Alegre showed mean incidence rates nearly three times higher than in Fortaleza, both in males and females, in 1990 to 1999 (Table 3). 
Quality indicators for the Population-Based Cancer Registries (PBCR) in Fortaleza and Porto Alegre, Brazil, for colorectal cancer, by gender, 1995 to 1999 .

\begin{tabular}{|c|c|c|c|c|c|c|}
\hline & \multicolumn{2}{|c|}{ Histological verification (\%) } & \multicolumn{2}{|c|}{$\begin{array}{c}\text { Cases diagnosed only by } \\
\text { Death Certificates (\%) }\end{array}$} & \multicolumn{2}{|c|}{$\begin{array}{c}\text { Mortality/Incidence } \\
\text { Ratio }\end{array}$} \\
\hline & Men & Women & Men & Women & Men & Women \\
\hline Porto Alegre PBCR & 67 & 65 & 22 & 25 & 53 & 52 \\
\hline Fortaleza PBCR & 80 & 81 & 16 & 14 & 37 & 44 \\
\hline
\end{tabular}

Sources: Mortality Information System - SIM, Ministry of Health (http://tabnet.datasus.gov.br/)

Table 2

Descriptive characteristics of colorectal cancer in the cities of Fortaleza and Porto Alegre, Brazil, 1990 to 1999 , by gender

\begin{tabular}{|c|c|c|c|}
\hline Characteristics & Gender & Fortaleza & Porto Alegre \\
\hline \multicolumn{4}{|l|}{ New cases } \\
\hline & Men & 475 & 1,295 \\
\hline & Women & 544 & 1,601 \\
\hline \multicolumn{4}{|c|}{$>60$ years of age [\%] } \\
\hline & Men & 61 & 66 \\
\hline & Women & 53 & 70 \\
\hline \multicolumn{4}{|c|}{ Age unknown [\%] } \\
\hline & Men & 2 & 1 \\
\hline & Women & 1 & 1 \\
\hline \multicolumn{4}{|c|}{ Anatomical site * } \\
\hline \multicolumn{4}{|c|}{ Colon (C18) [\%] } \\
\hline & Men & 49 & 63 \\
\hline & Women & 53 & 69 \\
\hline \multicolumn{4}{|c|}{ Rectosigmoid junction (C19) [\%] } \\
\hline & Men & 8 & 10 \\
\hline & Women & 5 & 7 \\
\hline \multicolumn{4}{|c|}{ Rectum (C20) [\%] } \\
\hline & Men & 43 & 27 \\
\hline & Women & 42 & 24 \\
\hline
\end{tabular}

Source: SisBasepop (National Cancer Institute, Rio de Janeiro, Brazil; http://www.inca.gov.br/cgi/sisbasepop.asp).

*According to the codes of the International Classification of Diseases, 10th revision (ICD-10).

The cities showed a positive EAPC for males and females. In Fortaleza, the overall EAPC pointed to an increase in incidence in males that was twice that in females. When broken down by age group, the over-60-year group was mainly res-ponsible for the observed increase in men. In Porto Alegre, the overall EAPC showed a balanced increase in incidence between the genders (Table 4).

\section{Discussion}

In 2005, World Health Organization (WHO) guidelines highlighted the importance of cancer prevention and control, in addition to PBCRs as databases for incident cases 11 .

The databases analyzed here showed quality indicators that are consistent with those observed in Volume 8 of the publication Cancer Incidence in Five Continents 5 for population-based cancer registries in Latin America. 
Figure 1

Mean age-specific rates and mean age-adjusted log-rates * for colorectal cancer in men and women. Fortaleza and Porto Alegre, Brazil, 1990 to 1999.

1a) Mean age-specific rates

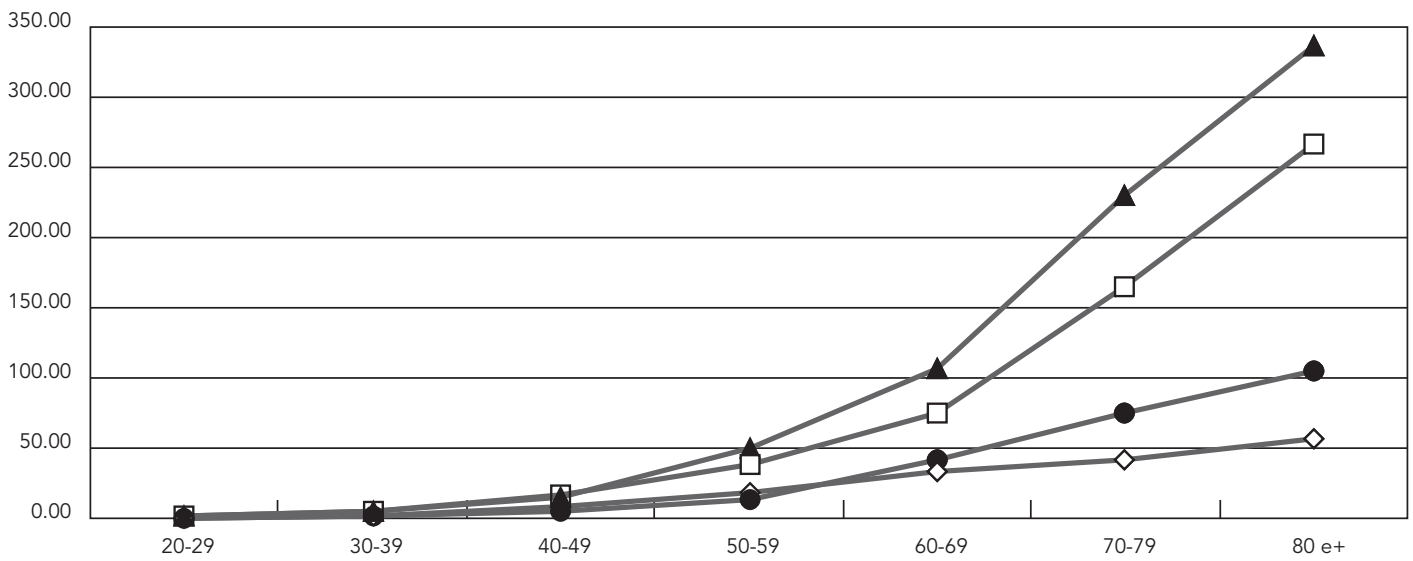

- Men - Fortaleza

$\neg$ Men - Porto Alegre

$\diamond$ Women - Fortaleza

$\rightarrow-$ Women - Porto Alegre

1b) Mean age-adjusted log-rates

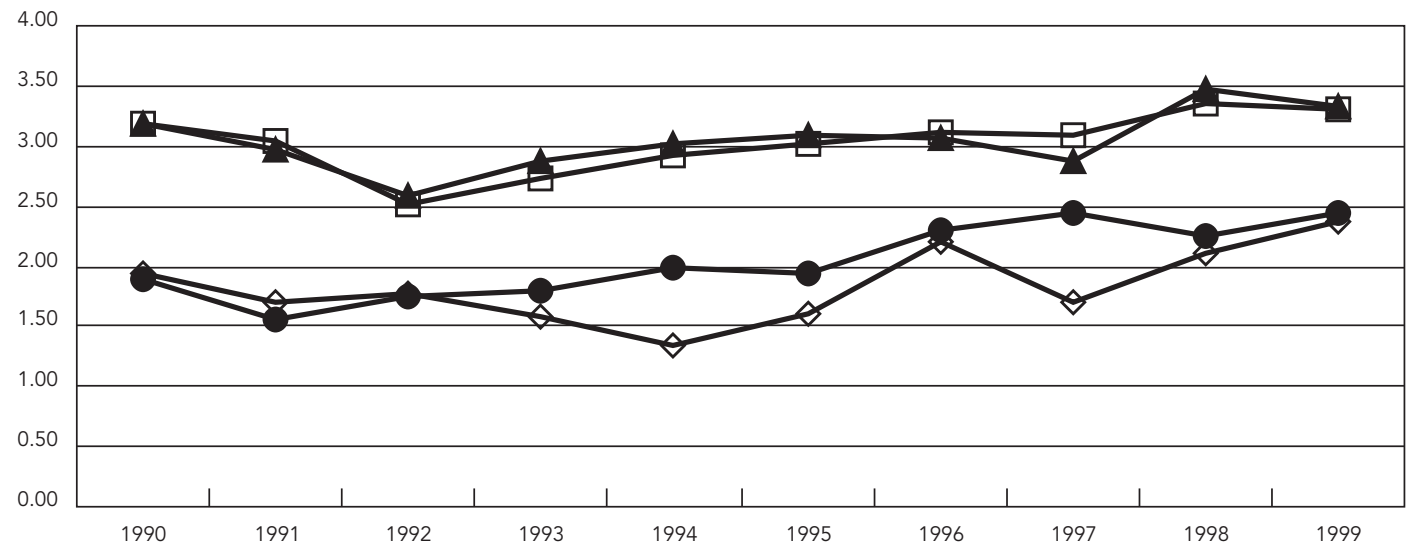

$\multimap$ Men - Fortaleza
$\neg$ Men - Porto Alegre
$\checkmark-$ Women - Fortaleza
$\neg-$ Women - Porto Alegre

Source: SisBasepop (National Cancer Institute, Rio de Janeiro, Brazil; http://www.inca.gov.br/cgi/sisbasepop.asp).

* World standard population as proposed by Segi 7 and modified by Doll et al. ${ }^{8}$.

Due to difficulties in obtaining information on population incidence, the studies tend to be based on information on cancer mortality. However, using data on the deaths alone as the basis for knowledge on the occurrence of malignant neoplasms does not allow a real understanding of the problem's magnitude, since there are important differences in case fatality and survival for each of them. In this sense, access to information on incidence is crucial for defining the role of risk factors and setting priorities for preven- tion and health services planning, management, and evaluation 2,12 . Studies on incidence trends allow an analysis of the relationship between risk factors and prognosis, considering changes in diagnostic methods and cancer classification over time, besides permitting comparisons of populations with different characteristics.

This study found an increase in colorectal cancer incidence in Fortaleza and Porto Alegre, in both men and women. Differences were found in the mean age-adjusted incidence rates for 
Mean age-adjusted incidence rates * for colorectal cancer in Fortaleza and Porto Alegre, Brazil, 1990 to 1999.

\begin{tabular}{|c|c|c|c|c|}
\hline \multirow[t]{2}{*}{ Gender } & \multicolumn{2}{|c|}{ Fortaleza } & \multicolumn{2}{|c|}{ Porto Alegre } \\
\hline & Mean incidence rate & $95 \% \mathrm{Cl}$ & Mean incidence rate & $95 \% \mathrm{Cl}$ \\
\hline Men & 8.6 & $7.8-9.4$ & 25.1 & $23.7-26.5$ \\
\hline Women & 7.1 & $6.5-7.7$ & 19.9 & $19.9-20.9$ \\
\hline
\end{tabular}

Source: SisBasepop (National Cancer Institute, Rio de Janeiro, Brazil; http://www.inca.gov.br/cgi/sisbasepop.asp).

* World standard population as proposed by Segi 7 and modified by Doll et al. 8.

Table 4

Estimated annual percent change (EAPC) in colorectal cancer incidence rates in Porto Alegre and Fortaleza, Brazil, in men and women, 1990 to 1999.

\begin{tabular}{|c|c|c|c|c|c|}
\hline \multirow[t]{2}{*}{ Age (years) } & \multirow[t]{2}{*}{ Gender } & \multicolumn{2}{|c|}{ Fortaleza } & \multicolumn{2}{|c|}{ Porto Alegre } \\
\hline & & EAPC & $p$-value & EAPC & p-value \\
\hline \multicolumn{6}{|l|}{$0-59$} \\
\hline & Male & 5.1 & 0.188 & 5.5 & 0.110 \\
\hline & Female & 6.1 & 0.076 & 4.3 & 0.173 \\
\hline \multicolumn{6}{|l|}{$\geq 60$} \\
\hline & Male & 10.4 & 0.001 & 3.6 & 0.207 \\
\hline & Female & 5.0 & 0.345 & 4.7 & 0.129 \\
\hline \multicolumn{6}{|l|}{ Total } \\
\hline & Male & 9.3 & $<0.001$ & 4.2 & 0.141 \\
\hline & Female & 5.3 & 0.147 & 4.6 & 0.106 \\
\hline
\end{tabular}

Source: SisBasepop (National Cancer Institute, Rio de Janeiro, Brazil; http://www.inca.gov.br/cgi/sisbasepop.asp).

colorectal cancer, which were larger in Porto Alegre than in Fortaleza. In both cities, the rates were higher in men than in women.

Concerning anatomical site, the study showed a similarity between men and women, unlike Parkin et al. 1, who only showed a similarity between the genders for colon cancer, since they found that rectal cancer was more frequent in men.

Regarding age, most studies reported higher incidence in individuals over 50 years of age, thus corroborating the current study's findings, in which incidence begins to appear in the 50-59year age group 13,14,15.

EAPC is a simple and easy-to-interpret method that has been used for trend analysis. Other studies using EAPC have shown findings similar to ours in relation to trend. Crocetti et al. 16 investigated cancer incidence trends in Italy (1986 to 1997) and showed an upward trend in colon cancer in both men (EAPC $=+2.5$ ) and women (EAPC $=+0.9$ ). Incidence of rectal cancer was fairly stable in both genders 15 .
Ponz de Leon et al. 14 investigated the colorectal cancer incidence trend in the city of Modena (in northern Italy) in 1984 to 1998 and detected an upward trend $33.7 \%$ higher incidence in the last triennium as compared to the first). The increase occurred in both genders, but the rates in women were significantly lower than in men.

According to Kamangar et al. 17, colorectal cancer incidence rates increased from 1973 to 1997 in various countries, except the United States, which showed a peak rate in the 1980s that later started to decline. They also found an incidence rate approximately fourfold higher in developed as compared to developing countries. This finding is similar to that of the present study, in which Porto Alegre, one of the cities with the highest human development indices in Brazil 18, showed mean rates nearly three-fold higher than in Fortaleza for both genders. However, the increase in incidence was greater in Fortaleza, especially among men. 
The upward trend in colorectal cancer incidence observed in some studies 14,16,19 may be due to the fact that this type of cancer is now diagnosed more frequently than in the past, thanks to technological improvements and the introduction of screening programs in other countries 19. Although Brazil still lacks a structured screening program for colorectal cancer, the necessary diagnostic tests have already been incorporated into the public and private health systems and are much more widely accessible than in the past.

In Brazil, the highest mean age-adjusted annual colorectal cancer incidence rates per 100 thousand men were found in more developed cities like São Paulo, 36.6 (1997 to 2000), Porto Alegre, 29.6 (1996 to 2000), and Campinas, São Paulo State, 28.5 (1991 to 1995). The highest rates per 100 thousand women were in Porto Alegre, 30.6 (1996 to 2000), São Paulo, 28.6 (1997 to 2000), and Campinas, 23.3 (1991 to 1995). The lowest mean rates were in the city of Palmas, Tocantins State (2000 to 2001), and Belém, Pará State (1996 to 1998), with 3.4 and $4.9 / 100$ thousand men and 6.0 and $6.1 / 100$ thousand women, respectively 20 .

The highest mean colorectal cancer incidence rates were observed in the city of Porto Alegre. Regional variations may reflect the heterogeneity in risk factor exposure profiles and may also be affected by differences in the health services' diagnostic capability, which can lead to underestimation of the real incidence in some regions of the country 4 .

In terms of cancer prevention, diagnosis, and treatment, Fortaleza has two secondarylevel health units with cancer prevention and early detection programs. It also has a specialized reference hospital, a university hospital, 15 general hospitals, a radiotherapy clinic, five chemotherapy services, six pathology laboratories, and other non-specialized healthcare services. In Porto Alegre the programs and services are provided mainly by 23 public and private hospitals, of which six are high-complexity cancer centers 3 . The supply of diagnostic and therapeutic services (both public and private) is thus superior in Porto Alegre, which means that the population has better access to health services than in Fortaleza.

As for medical care coverage, based on the available data from the Unified National Health System (SUS) 18, during the reference period (1995 to 1999) the mean annual number of medical consultations per inhabitant in the SUS was higher in Porto Alegre (Fortaleza: 2.1; Porto Alegre: 3.2). Another indicator shows that the proportion of the population covered by private plans was more than eight percentage points higher in Porto Alegre in 2000 to 2005 (Fortaleza: 20.6\%; Porto Alegre: $29 \%$ ). These indicators demonstrate (although indirectly) the difference in access to diagnostic and therapeutic services.

Strategies for prevention and early detection should consider the existing differences in the country, given that the increase in colorectal cancer incidence in Fortaleza (Northeast Brazil) was twice as high in men, while in Porto Alegre (in the South) the increase in incidence among older women was already slightly higher than in men.

The two State capitals, one in the South (Porto Alegre) and the other in the Northeast (Fortaleza), display different socioeconomic and cultural characteristics and can thus be used as proxies for their respective geographic regions, thus allowing better targeting of public health polices and priority-setting, resulting in fairer allocation of resources and efforts with a view towards improving the Brazilian population's health conditions.

A study by Neves et al. 21 that correlated colorectal cancer mortality in 1980 to 1997 with prior food intake patterns showed that the State capitals of the South, Southeast, and CentralWest had higher consumption of calories and cereals, while this consumption was below average in the North and Northeast. Porto Alegre showed the highest meat consumption, about twice that of Fortaleza. A direct association was observed between fat and meat intake and colorectal cancer mortality rates 21 . As for risk factors, the household survey on risk behaviors and selfreported non-communicable chronic diseases showed that alcohol intake, smoking prevalence, and obesity were higher in Porto Alegre than in Fortaleza 4 , corroborating the findings from other studies 21,22,23,24,25.

The higher increase in incidence in Fortaleza, especially among men, may reflect an increase in the number of cases of the disease due to recent changes in eating habits, high prevalence of sedentary lifestyle, and increase in obesity.

Risk groups were identified that deserve more targeted attention in order for the prevention and screening programs to act more effectively and provide backing for the formulation of hypotheses to be investigated in the future. 


\section{Resumo}

O objetivo foi descrever a distribuição da incidência de câncer de cólon e reto em Fortaleza, Ceará, e Porto Alegre, Rio Grande do Sul, no Brasil, e a tendência temporal da doença entre 1990-1999. Foram calculadas taxas médias anuais de incidência ajustadas por idade e a variação percentual anual estimada (estimated annual percent change-EAPC) das taxas, por sexo, utilizando-se os registros de câncer de base populacional. O EAPC apontou aumento das taxas em Porto Alegre e Fortaleza para homens, $+4,2 \%(p=0,14) e+9,3 \%$ ( $p \leq 0,001)$, e mulheres, $+4,6 \%(p=0,11) e+5,3 \%$ ( $p=$ $0,15)$, respectivamente. As taxas médias de incidência ajustadas foram cerca de três vezes maiores em Porto Alegre do que em Fortaleza, tanto para homens (25,1 vs. 8,6/100 mil) quanto para mulheres (19,9 vs. 7,1/100 mil). O aumento das taxas de incidência pode ser devido a estratégias de detecção precoce do câncer, mudanças no estilo de vida das pessoas e a alterações da estrutura etária da população. Um perfil populacional semelhante ao de países desenvolvidos pode justificar as maiores taxas de incidência encontradas em Porto Alegre. Apesar disso, Fortaleza apresentou os maiores incrementos para o período.

Neoplasias Colorretais; Registros de Doenças; Incidência

\section{References}

1. Parkin DM, Bray FI, Devesa SS. Cancer burden in the year 2000. The global picture. Eur J Cancer 2001; 37 Suppl 8:S4-66.

2. Instituto Nacional de Câncer. Estimativa 2006: incidência de câncer no Brasil. Rio de Janeiro: Instituto Nacional de Câncer; 2005.

3. Instituto Nacional de Câncer. Câncer no Brasil: dados dos registros de câncer de base populacional. v. 3. Rio de Janeiro: Instituto Nacional de Câncer: 2003.

4. Instituto Nacional de Câncer. Inquérito domiciliar sobre comportamentos de risco e morbidade referida de doenças e agravos não transmissíveis: Brasil, 15 capitais e Distrito Federal, 2002-2003. Rio de Janeiro: Instituto Nacional de Câncer; 2004.

5. Parkin DM, Whelan SL, Ferlay J, Teppo L, Thomas DB, editors. Cancer incidence in five continents. v. VIII. Lyon: International Agency for Research on Cancer; 2002. (IARC Scientific Publications, 155).

6. Holten VV, Percy C. ICD-9 TO ICD-10. Washington DC: Department of Health and Human Services, National Institutes of Health; 1995.

\section{Contributors}

R. S. Reis, M. O. Santos, and K. V. Bloch participated in the planning, analysis, discussion, and editing of the article. R. S. Reis and M. O. Santos contributed to the data collection. K. V. Bloch collaborated in the study's supervision. All the authors participated fully or partially in each phase of the study.

\section{Acknowledgments}

The authors wish to thank the Porto Alegre PopulationBased Cancer Registry and its coordinator Dr. Paulo Recena Grassi and the Fortaleza Population-Based Cancer Registry and its coordinator Dr. Miren Maite Arregi Uribe.
7. Segi M. Cancer mortality for selected sites in 24 countries (1950-57). Sendai: Department of Public Health, Tohoku University School of Medicine; 1960.

8. Doll R, Payne P, Waterhouse JAH. Cancer incidence in five continents. v. I. Berlin: Springer-Verlag; 1966.

9. Coordenadoria de Programas de Controle do Câncer, Secretaria Nacional de Assistência à Saúde, Instituto Nacional de Câncer. Registro de câncer: princípios e métodos. Rio de Janeiro: Instituto Nacional de Câncer; 1995.

10. Ries LAG, Eisner MP, Kosary CL, Hankey BF, Miller BA, Clegg L, editors. SEER cancer statistics review, 1973-1999. http://seer.cancer.gov/csr/1973_1999/ (accessed on 01/Dec/2002).

11. World Health Organization. Cancer prevention and control. http://www.who.int/nmh/a5816/en/ index.html (accessed on 30/Jul/2006).

12. Pinto FG, Curi PR. Mortalidade por neoplasias no Brasil (1980/1983/1985): agrupamento dos estados, comportamento e tendências. Rev Saúde Pública 1991; 25:276-81. 
13. Ansari R, Mahdavinia M, Sadjadi A, Nouraie M, Kamangar F, Bishehsari F, et al. Incidence and age distribution of colorectal cancer in Iran: results of a population-based cancer registry. Cancer Lett 2006; 240:143-7.

14. Ponz de Leon M, Marino M, Benatti P, Rossi G, Menigatti M, Pedroni M, et al. Trend of incidence, subsite distribution and staging of colorectal neoplasms in the 15-year experience of a specialised cancer registry. Ann Oncol 2004; 15:940-6.

15. Schottenfeld D, Winawer SJ. Cancers of large intestine. In: Schottenfeld D, Fraumeni Jr. JF, editors. Cancer epidemiology and prevention. Oxford: Oxford University Press; 1996. p. 813-40.

16. Crocetti E, Capocaccia R, Casella C, Guzzinati S, Ferretti S, Rosso S, et al. Population-based incidence and mortality cancer trends (1986-1997) form the network of Italian cancer registries. Eur J Cancer Prev 2004; 13:287-95.

17. Kamangar F, Dores GM, Anderson WF. Patterns of cancer incidence, mortality, and prevalence across five continents: defining priorities to reduce cancer disparities in different geographic regions of the world. J Clin Oncol 2006; 24:2137-50.

18. Departamento de Informática do SUS. Indicadores e dados básicos para a saúde no Brasil: base de dados (2005). http://tabnet.datasus.gov.br/cgi/ idb2005/matriz.htm (accessed on 06/Oct/2006).
19. Levi F, Te VC, Randimbison L, La Vecchia C. Trends in cancer incidence and mortality in Vaud, Switzerland, 1974-1993. Ann Oncol 1996; 7:497-504.

20. Instituto Nacional de Câncer. A situação do câncer no Brasil. http://www.inca.gov.br/situacao (accessed on 15/Dec/2006).

21. Neves FJ, Koifman RJ, Mattos IE. Mortalidade por câncer de cólon e reto e consumo alimentar em capitais brasileiras selecionadas. Rev Bras Epidemiol 2006; 9:112-20.

22. American Cancer Society. Colorectal cancer facts \& figures: special edition 2005. Atlanta: American Cancer Society; 2005.

23. Hu FB, Willett WC, Li T, Stampfer MJ, Colditz GA, Manson JE. Adiposity as compared with physical activity in predicting mortality among women. $\mathrm{N}$ Engl J Med 2004; 351:2694-703.

24. Calle EE, Rodriguez C, Walker-Thurmond K, Thun MJ. Overweight, obesity, and mortality from cancer in a prospectively studied cohort of U.S. adults. N Engl J Med 2003; 348:1625-38.

25. Lopes ECF, Derivi SCN, Mendez MHM. Importância da dieta na epidemiologia do câncer de cólon e reto. Rev Saúde Pública 1984; 18:405-10.

Submitted on $25 / \mathrm{Jan} / 2008$

Final version resubmitted on 02/May/2008

Approved on 07/May/2008 